\title{
Vasoactive Intestinal Peptide Prevents Excitotoxic Cell Death in the Murine Developing Brain
}

\author{
Pierre Gressens, ${ }^{*}$ Stéphane Marret, ${ }^{\ddagger}$ Joanna M. Hill,§ Douglas E. Brenneman, ${ }^{\S}$ Illana Gozes," Mati Fridkin," \\ and Philippe Evrard* \\ *Service de Neuropédiatrie, Hôpital Robert-Debré and Faculté Xavier Bichat, F-75019 Paris, France; ${ }^{\ddagger}$ Service de Néonatologie, Hôpital \\ Charles Nicolle, 76000 Rouen, France; ${ }^{\S}$ Section on Developmental and Molecular Pharmacology, Laboratory of Developmental \\ Neurobiology, National Institutes of Child Health and Human Development, Bethesda, Maryland 20892; "Department of Clinical \\ Biochemistry, Tel Aviv University, Tel Aviv, Israel 69978; and "Department of Organic Chemistry, Weizmann Institute, Rehovot, \\ Israel 78100
}

\begin{abstract}
Excitotoxic damage may be a critical factor in the formation of brain lesions associated with cerebral palsy. When injected at birth, the glutamatergic analog ibotenate induces mouse brain lesions that strikingly mimic human microgyria. When ibotenate is injected at postnatal day 5 , it produces transcortical necrosis and white matter cysts that mimic human perinatal hypoxic-like lesions. Vasoactive intestinal peptide (VIP) has potent growth-related actions and neuroprotective properties that influence mitosis and neuronal survival in culture. The goal of this study was to assess the protective role of VIP against excitotoxic lesions induced by ibotenate in developing mouse brain. VIP cotreatment reduced ibotenate-induced microgyric-like cortical lesions and white matter cysts by up to 77 and $85 \%$, respectively. VIP protective effects were reproduced by a peptide derived from activity-dependent neurotrophic factor (ADNF), a trophic factor released by VIP-stimulated astrocytes, and by stearyl norleucine VIP, a specific VIP agonist that does not activate adenylate cyclase. Neither forskolin, an adenylate cyclase activator, nor pituitary adenylate cyclase-activating peptide, provided VIP-like protection. VIP and neurotrophic analogs, acting through a cAMP-independent mechanism and inducing ADNF release, could represent new avenues in the understanding and prevention of human cerebral palsy. (J. Clin. Invest. 1997. 100:390-397.) Key words: activity-dependent neurotrophic factor - cerebral palsy $\bullet$ ibotenic acid $\cdot N$-methyl-D-aspartate $\bullet$ vasoactive intestinal peptide
\end{abstract}

\section{Introduction}

Although prenatal and perinatal care have greatly improved neonatal mortality and morbidity in the last $40 \mathrm{yr}$, cerebral palsy remains prevalent with an increasing incidence in some western countries (1), due in part to the increased survival of extremely low birth weight infants (2). The pathophysiology of cerebral palsy has been revisited during the last decade (3-8). The current hypothesized etiology, rather than being limited

Address correspondence to Dr. Pierre Gressens, Service de Neuropédiatrie, Hôpital Robert-Debré, 48 Blvd. Sérurier, F-75019 Paris, France. Phone: 33-1-40-03-47-83; FAX: 33-1-40-03-47-74; E-mail: pierre.gressens@rdb.ap-hop-paris.fr

Received for publication 6 September 1996 and accepted in revised form 11 April 1997.

The Journal of Clinical Investigation

Volume 100, Number 2, July 1997, 390-397 to hypoxic-ischemic mechanisms, seems to be multifactorial, involving several preconceptional and prenatal factors, possibly including hypoxia/perfusion failure, thyroid hormone deficiency, growth factor deficiency, and maternal infection producing excess cytokines. For several risk factors of cerebral palsy, excitatory amino acids could represent a common final pathway leading to neural cell damage and death (for review see reference 9). We recently used ibotenate, a glutamatergic agonist, to produce an animal model of excitotoxic brain lesions (10). When administered soon after completion of neuronal migration to the infragranular layers, ibotenate induces lesions that mimic microgyria, a cortical lesion for which an etiological event (when diagnosed) is more frequently found between 14 and 28 wk of human gestation $(11,12)$. When ibotenate is administered after all neurons have completed migration in the neocortex, a spectrum of cortical-subcortical injuries is produced that strikingly mimics cortical damage (transcortical necrosis) observed more frequently in babies born after 32 wk of gestation in humans $(13,14)$, and also certain types of periventricular leukomalacias (white matter cystic lesions) most frequently observed in fetuses and preterm neonates between 24 and 32 postconceptional wk $(8,15,16)$. Furthermore, in this mouse model, magnesium sulfate was shown to prevent neural cell death, demonstrating the usefulness of such methodological tools for designing future clinical intervention studies (17).

Vasoactive intestinal peptide (VIP), ${ }^{1}$ a 28 -amino acid peptide, is a central nervous system (CNS) neurotransmitter and neuromodulator with neurotrophic properties, including stimulation of astrocytic mitoses (18), increase of neuronal survival (19-21), and promotion of early embryonic growth $(22,23)$. Many trophic actions of VIP are indirect, occurring through the VIP-induced release of other factors such as activitydependent neurotrophic factor (ADNF) (24), IL-1 $\alpha$ (25), and protease nexin 1 (26), all of which are released from glial cells. VIP is a member of a superfamily of peptides including pituitary adenylate cyclase-activating polypeptide 1-38 (PACAP), which exhibits a high sequence homology with VIP. PACAP and VIP share some common receptors (for review see reference 27). Two transduction systems have been described for VIP: one mechanism involves stimulation of adenylate cyclase $(28,29)$, while the second pathway is independent from cAMP production (see Discussion). VIP has also recently been shown

1. Abbreviations used in this paper: ADNF, activity-dependent neurotrophic factor; CNS, central nervous system; NMDA, $N$-methyl-Daspartate; $\mathrm{P}$, postnatal day; PACAP, pituitary adenylate cyclase-activating polypeptide 1-38; SNV, stearyl norleucine vasoactive intestinal peptide; VA, vasoactive intestinal peptide antagonist; VIP, vasoactive intestinal peptide. 
to potentiate c-fos expression induced by low concentrations of glutamate in cultured cortical neurons (30), and to attenuate excitotoxic pulmonary edema (31), suggesting some interactions between transduction pathways of VIP and glutamate.

Together, these data prompted us to investigate, in developing mouse brain, the protective effects of VIP against neural cell death induced by intrapallial injections of ibotenate. VIP effects were compared with PACAP protection, and the transduction pathways involved in the protective mechanisms were evaluated by the use of specific agonists. Involvement of ADNF in the VIP effects was also tested in our model.

\section{Methods}

Drug administration and histological procedures. Pregnant NMRI (Naval Medical Research Institute; Centre d'Elevage R. Janvier, Le Genest-St. Isle, France) mice were housed in groups and fed with laboratory chow and water ad libitum. Several litters of mice pups of both sexes were used for the experiments. As previously described $(10,17)$, at postnatal day (P) 0 or P5, pups were anesthetized with ether inhalation and kept under a warming lamp. Intracerebral injections were performed with a 26-gauge needle on a 50- $\mu$ l Hamilton syringe mounted on a calibrated microdispenser. The needle was inserted $2 \mathrm{~mm}$ under the external surface of scalp skin in the frontoparietal area of the right hemisphere, $2 \mathrm{~mm}$ from the midline in the lateral-medial plane, and 2 (at P0) or 3 (at P5) mm (in the rostrocaudal plane) from the junction between the sagittal and lambdoid sutures. Histological analysis of brain tissues from $>1,500$ animals injected in our laboratory confirmed that these visual coordinates result in highly reproducible injections (Gressens, P., and S. Marret, personal communication). Two $1-\mu l$ boluses were injected at a 30 -s interval. The needle was left in place for an additional $30 \mathrm{~s}$. In cases where a second delayed injection was performed (see below), the initial site of injection was easily recognized because of the presence of a punctuate blood clot underneath the skin. In all these experiments, the tip of the needle reached the periventricular white matter (some animals injected with toluidine blue confirmed the correct positioning of the needle). After the injections, pups were allowed to recover from anesthesia, and were returned to their dams. $5 \mathrm{~d}$ later, the surviving pups were killed under ether anesthesia by intracardiac perfusion with $4 \%$ paraformaldehyde. The brains were removed and postfixed in the same fixative solution for an additional $24 \mathrm{~h}$ at $4^{\circ} \mathrm{C}$.

After fixation, the brains were dehydrated in alcohol and embedded in paraffin. $15-\mu \mathrm{m}$-thick coronal serial sections were cut, and every third section was stained with cresyl violet. Brain was completely and serially sectioned from the frontal pole to the occipital lobes. In theory, neocortical and white matter lesions can be defined by the maximal length of three orthogonal axes: the lateral-medial axis (in a coronal plane), the radial axis (also in a coronal plane, from the pial surface to the lateral ventricle), and the fronto-occipital axis (in a sagittal plane). Because of the difficulty of accurately evaluating the degree of damage to neurons in neocortical layers in the epicenter of the lesion focus, the radial axis did not appear as an objective measure of the lesion size. In preliminary studies (10; Gressens, P., and S. Marret, personal communication), we had shown an excellent correlation between the maximal size of the radial and fronto-occipital diameters of the ibotenic-induced lesions. Based on these observations, we sectioned serially the entire brain in the coronal plane. This sectioning permitted an accurate and reproducible determination of the maximal sagittal fronto-occipital diameter (which is equal to the number of sections where the lesion was present multiplied by 15 $\mu \mathrm{m})$, and was as an index of the volume of the lesion. In subsequent sections of this paper, this maximal diameter will be referred to as the length of the lesion in the sagittal fronto-parietal axis. Statistical analyses were performed by ANOVA with Dunnet's multiple comparison of means test. Results are expressed as means \pm SEM.

Experimental groups. Ibotenate (lot 94H37971; Sigma Chemical
Co., St. Louis, MO), VIP (Peninsula Laboratories, Inc., St. Helens, United Kingdom), PACAP (Peninsula Laboratories, Inc.) and neurotensin 1-6 VIP 7-28 hybrid, a VIP antagonist (VA) $(32,33)$, were diluted in $0.02 \%$ acetic acid, $0.1 \mathrm{M}$ phosphate buffer saline. Stearyl norleucine VIP (SNV) $(a)$ was diluted in $0.002 \%$ acetic acid $/ 0.008 \%$ dimethyl sulfoxide $/ 8 \%$ ethanol and forskolin (an adenylate cyclase activator) (BIOMOL Research Labs, Inc., Plymouth Meeting, PA), (b) was diluted in $0.01 \%$ acetic acid $/ 0.05 \%$ dimethyl sulfoxide $/ 0.1 \mathrm{M}$ phosphate buffer saline. ADNF was diluted in $0.1 \mathrm{M}$ phosphate buffer saline. Heat-inactivated VIP, used as a control peptide, was heated at $65^{\circ} \mathrm{C}$ for $45 \mathrm{~min}$, and diluted the same as active VIP.

Ibotenate, a glutamate analog extracted from the Muscarina amanita mushroom, activates both $N$-methyl-D-aspartate (NMDA) and metabotropic receptors, but not the alpha-3-amino-hydroxy-5methl-4-isoxazole (AMPA) and kainate receptors.

VA, a hybrid peptide consisting of a carboxy fragment of VIP (VIP 7-28) and a six-amino acid fragment of neurotensin, was synthesized and purified as previously described $(32,33)$. This antagonist has no agonist activity, and can distinguish between central and peripheral VIP receptors (33). Previous studies have shown that VA treatment of CNS cultures produced a $30 \%$ loss in the number of neurons (32). Injection of VA to pregnant mice at early stages of brain development induced a 50\% microcephaly in the embryos (23). Administration of VA to neonatal animals caused damage to cerebral cortical neurons (34) as well as delays in the acquisition of developmental milestones (35). Importantly, cotreatment with neurotensin did not influence the biological activity associated with VA (35).

SNV is a novel agonist of VIP, exhibiting $(a)$ a 100 -fold greater potency than the parent molecule, and (b) specificity for a VIP receptor associated with neuronal survival (36). This VIP analog acts through cAMP-independent mechanisms $(36,37)$. The new molecule contains two chemical modifications in VIP: the addition of an $\mathrm{NH}_{2}-$ terminal long-chain fatty acid, and the substitution of the methionine in position 17 with norleucine. Synthesis and purification of SNV was performed as previously described (38).

Table I. Mortality Rate

\begin{tabular}{|c|c|c|}
\hline \multirow[b]{2}{*}{ Experimental groups } & \multicolumn{2}{|c|}{ Mortality } \\
\hline & P0 & P5 \\
\hline Ibotenate & $4 / 30$ & $1 / 17$ \\
\hline Ibotenate + VIP $1 \mu \mathrm{g}$ & $1 / 25$ & $4 / 15$ \\
\hline Ibotenate + VIP $0.1 \mu \mathrm{g}$ & $1 / 6$ & $0 / 6$ \\
\hline Ibotenate + VIP $0.01 \mu \mathrm{g}$ & $0 / 6$ & $0 / 6$ \\
\hline Ibotenate + VIP $1 \mu \mathrm{g}$ heat inactivated & $1 / 6$ & $1 / 6$ \\
\hline Ibotenate + PACAP $1 \mu \mathrm{g}$ & $1 / 8$ & $1 / 9$ \\
\hline Ibotenate + PACAP $0.1 \mu \mathrm{g}$ & $3 / 8$ & $0 / 6$ \\
\hline Ibotenate + PACAP $0.01 \mu \mathrm{g}$ & $1 / 8$ & $0 / 6$ \\
\hline Ibotenate + PACAP $0.001 \mu \mathrm{g}$ & $2 / 8$ & $0 / 6$ \\
\hline Ibotenate + VA $1 \mu \mathrm{g}$ & $3 / 8$ & $0 / 7$ \\
\hline Ibotenate + SNV $0.1 \mu \mathrm{g}$ & $1 / 7$ & $1 / 8$ \\
\hline Ibotenate + VIP $1 \mu \mathrm{g}+$ VA $1 \mu \mathrm{g}$ & $0 / 6$ & $0 / 6$ \\
\hline Ibotenate + forskolin $5 \mu \mathrm{g}$ & $0 / 6$ & $0 / 5$ \\
\hline Ibotenate + forskolin $0.5 \mu \mathrm{g}$ & $0 / 7$ & $1 / 6$ \\
\hline Ibotenate + forskolin $0.05 \mu \mathrm{g}$ & $1 / 6$ & $1 / 5$ \\
\hline Ibotenate + ADNF $10 \mathrm{pg}$ & $0 / 6$ & $0 / 5$ \\
\hline Ibotenate + ADNF 1 pg & $0 / 6$ & $0 / 6$ \\
\hline Ibotenate + ADNF $0.1 \mathrm{pg}$ & $1 / 6$ & $0 / 6$ \\
\hline Ibotenate + VIP $1 \mu \mathrm{g} 2 \mathrm{~h}$ later & $0 / 6$ & $0 / 6$ \\
\hline Ibotenate + VIP $1 \mu \mathrm{g} 4 \mathrm{~h}$ later & $0 / 5$ & $4 / 11$ \\
\hline Ibotenate + VIP $1 \mu \mathrm{g} 8 \mathrm{~h}$ later & $0 / 5$ & $0 / 6$ \\
\hline Total & $20 / 179$ & $14 / 154$ \\
\hline
\end{tabular}


ADNF-14 is a 14-amino acid peptide derived from activity-dependent neurotrophic factor, a protein released from astroglia by VIP (24). The structure of ADNF-14 is VLGGGSALLRSIPA. Peptide synthesis was conducted on a solid support, and the product was purified on Sephadex G-25 and reversed HPLC. The peptide showed the desired molar ratios of amino acids. This peptide has similar neuroprotective properties to that of intact ADNF. ADNF-14 has been shown to protect CNS neurons from NMDA, beta amyloid peptide, and gp120, the envelope protein from the human immunodeficiency virus. The peptide was dissolved in PBS just before injection.

In the first set of experiments, ibotenate $(5 \mu \mathrm{g}$ at $\mathrm{P} 0$ and $10 \mu \mathrm{g}$ at P5) was coinjected with one of the following peptides or combination of peptides: $1,0.1$, or $0.01 \mu \mathrm{g}$ VIP; $1 \mu \mathrm{g}$ heat-inactivated VIP; $1 \mu \mathrm{g}$ VIP + $1 \mu \mathrm{g}$ VA; $1,0.1,0.01$, or $0.001 \mu \mathrm{g}$ PACAP; $0.1 \mu \mathrm{g} \mathrm{SNV;} \mathrm{5,} \mathrm{0.5,}$ or $0.05 \mu \mathrm{g}$ forskolin; 10,1 , or $0.1 \mathrm{pg}$ ADNF; controls received only ibotenate.

In another set of experiments, $\mathrm{P} 0$ and $\mathrm{P} 5$ pups were injected with ibotenate ( 5 or $10 \mu \mathrm{g}$, respectively) followed by an injection, in the same site, of $1 \mu \mathrm{g}$ VIP 2, 4, or $8 \mathrm{~h}$ after the ibotenate injection.

5-23 pups from at least two different litters were used in each experimental group. Values were obtained from two or more successive experiments.

VIP binding sites analysis. The heads of untreated $\mathrm{P} 0$ and $\mathrm{P} 5$ pups were frozen rapidly at $-80^{\circ} \mathrm{C}$. $20-\mu \mathrm{m}$ cryostat sections were pro- cessed for binding with [ $\left.{ }^{125} \mathrm{I}\right]-\mathrm{VIP}$, and for subsequent autoradiography as previously described (39). Sections were incubated in $\left[{ }^{125} \mathrm{I}\right]$ VIP with and without $1 \mu \mathrm{M}$ VIP (Peninsula Laboratories, Inc.) or $1 \mu \mathrm{M}$ SNV. The density of labeled VIP in the neocortex was analyzed by digitizing the film images using a Macintosh II-based image analysis system (IMAGE; Wayne Rasband, Research Services Branch, National Institutes of Mental Health, Bethesda, MD). Specific binding was determined by subtracting the light transmittance from brain sections incubated with $1 \mu \mathrm{M}$ unlabeled VIP from the total light transmittance.

\section{Results}

Mortality and epileptic manifestations. Overall mortality was low in the present study $(10.2 \%)$, both in P0 and P5 experiments (11.2 and $9.1 \%$, respectively) (Table I). The mortality rate observed with ibotenate is lower than previously observed (10), probably because of differences of activity in successive batches of ibotenate (Marret, S., and P. Gressens, personal communication). In the present study, all animals were injected with a single lot of ibotenate. No significant difference was observed in a test of contingency (exact Fisher test) when
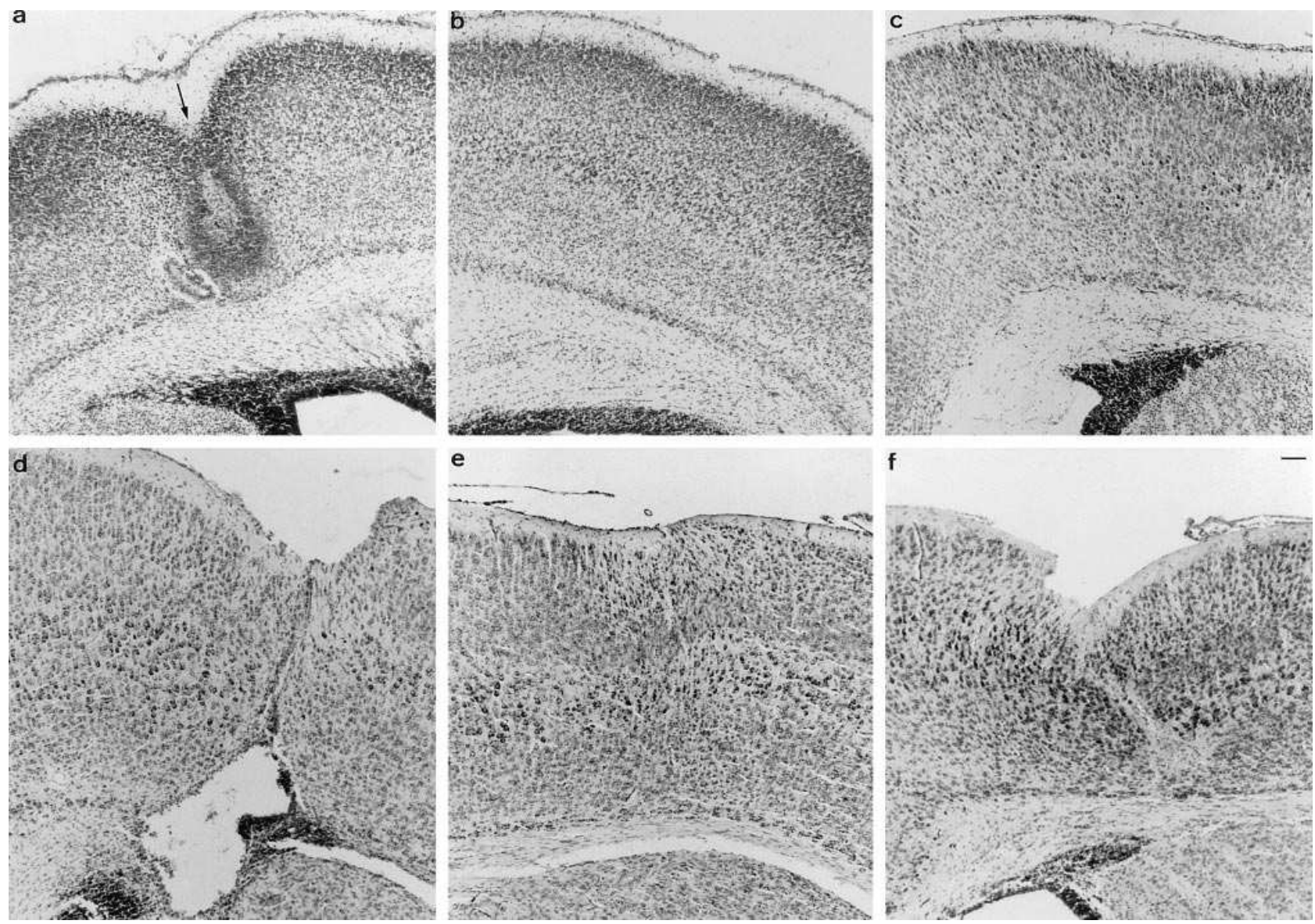

Figure 1. VIP prevents ibotenate-induced P0 neuronal death and P5 white matter cyst. Cresyl violet-stained sections showing brain lesions induced by ibotenate injected at P0 $(a-c)$ or P5 $(d-e)$ and studied at the age of P5 $(a-c)$ or P10 $(d-e)$. $(a)$ Brain injected with ibotenate alone, showing the typical neuronal loss predominating in layers V and VIa with the sulcus formation (arrow) and the absence of detectable white matter cystic lesion. ( $b$ and $c$ ) Brains cotreated with ibotenate and VIP $(b)$ or SNV $(c)$. Note the absence of detectable cortical lesion. (d) Brain injected with ibotenate alone, showing the typical neuronal loss in layers II-VI and the white matter cystic lesion. $(e$ and $f)$ Brains cotreated with ibotenate and VIP $(e)$ or SNV $(f)$. Note the absence of detectable white cystic matter lesion, but the persistence of neuronal loss in the cortical plate. Bar, $40 \mu \mathrm{m}$. 
A

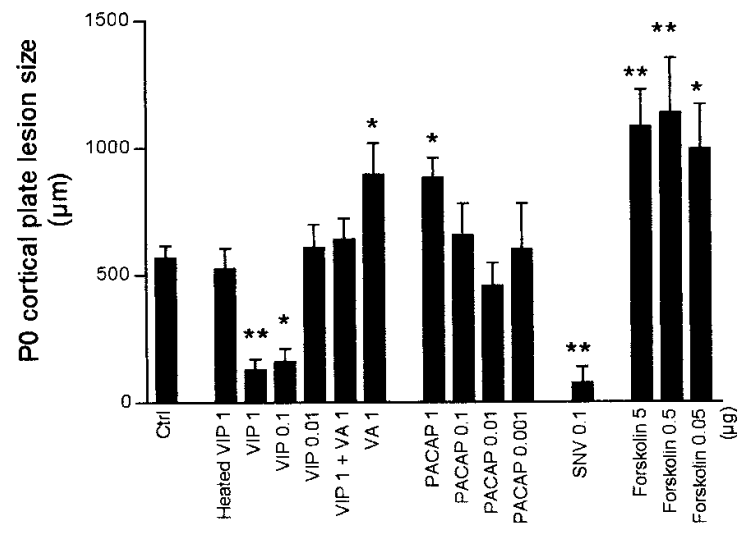

B

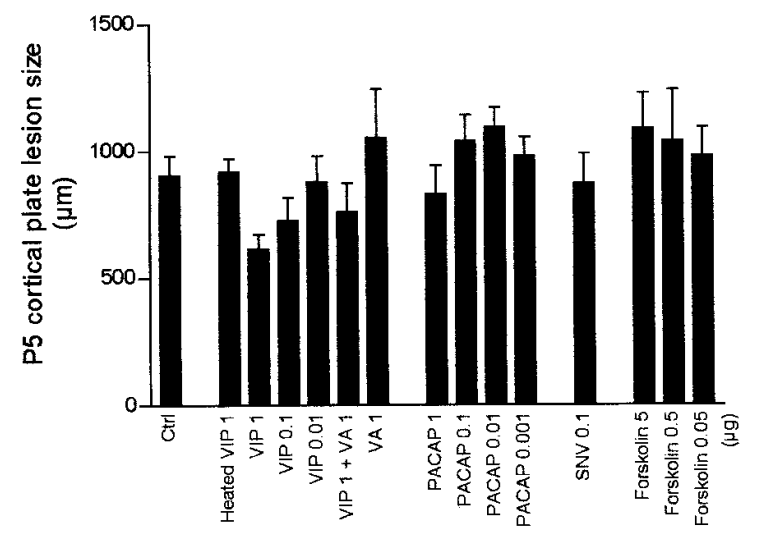

C

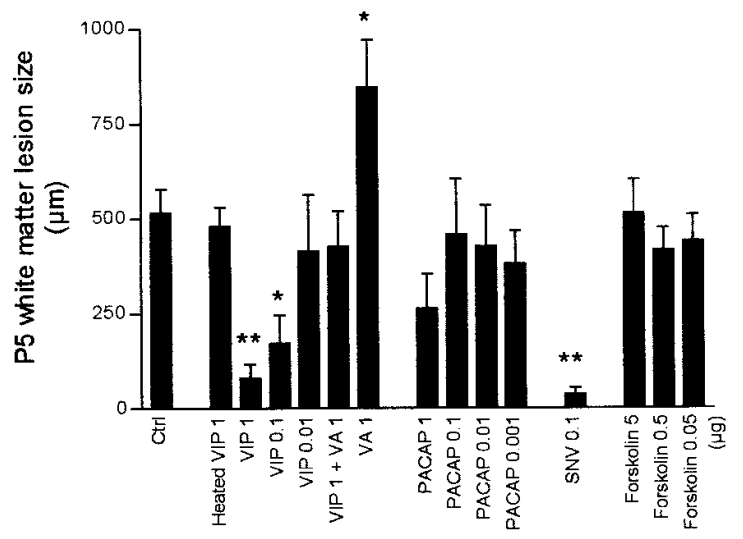

Figure 2. VIP and SNV display similar protective effects against neocortical lesions induced by ibotenate. Bar represents mean length of the neocortical lesion in the sagittal fronto-occipital axis \pm SEM. Asterisks indicate difference from control $(* P<0.05$, $* * P<0.01$ in ANOVA with Dunnet's multiple comparison test). Control animals $(C t r l)$ were injected with ibotenate alone; all the other experimental groups were cotreated with ibotenate and the indicated peptide(s) $(\mathrm{P}$, PACAP). (A) Size of the lesion observed in neuronal layers $\mathrm{V}$ and VIa after ibotenate injection at P0. (B) Size of the lesion observed in neuronal layers II-VI after ibotenate injection at P5. (C) Size of the cystic lesion observed in the white matter after ibotenate injection at P5. the different treatment groups were compared to the animals injected with ibotenate alone. Epileptic manifestations including clonic or tonic seizures and apneas were observed in almost all P0- and P5-treated animals. No difference in intensity, clinical phenotype, or incidence of epileptic manifestations was observed between the different experimental groups.

Protective effects of VIP against ibotenate injections performed at $P 0$. Brain serial sections stained with cresyl violet showed focal damage in $100 \%$ of the animals injected with ibotenate alone. All these brains displayed a dramatic neuronal loss predominating in neocortical layers V and VIa (Fig. $1 A$ ), without detectable white matter cystic lesion. Generally, a microgyric sulcus was present because of the infolding of the molecular and the upper cortical layers. The mean length \pm SEM of the ibotenate-induced cortical lesion along the sagittal fronto-parietal axis was 558 $\pm 44 \mu \mathrm{m}$ (Fig. $2 \mathrm{~A}$ ).

When different concentrations of VIP, but not heat-inactivated VIP, were coinjected with ibotenate, a dose-dependent reduction of the cortical lesion size was observed (71 and $77 \%$ decrease of the mean length of the lesion in the sagittal frontoparietal axis with 0.1 and $1 \mu \mathrm{g}$ VIP, respectively) (Fig. $1 B$ and Fig. $2 \mathrm{~A}$ ). With the highest dose of VIP, $47 \%$ of cotreated animals displayed completely normal cortex. In most of these normal brains, no needle tract was observed. The absence of needle tract is generally the case when early postnatal brain is injected with PBS alone (9). No protection of cortical neurons was obtained when VIP treatment was delayed after ibotenate administration (Fig. 3). SNV, a specific VIP agonist, remarkably mimicked the protective effects of VIP against excitotoxic cortical lesions $(86 \%$ lesion size reduction and absence of histological lesion in $60 \%$ of treated animals) (Fig. $1 C$ and Fig. 2 A). Cotreatment with VA, $1 \mu \mathrm{g}$ PACAP, or forskolin, exacerbated the excitotoxic lesion $(80,60$, and $99-127 \%$, respectively, increase of mean cortical lesion size in the sagittal

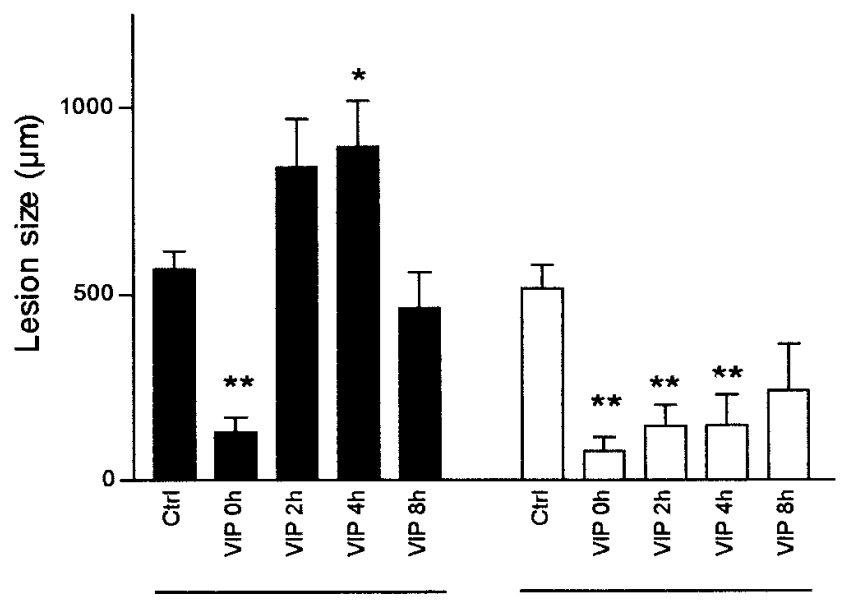

PO cortical plate

P5 w hite matter

Figure 3. VIP protects against white matter excitotoxic lesions $4 \mathrm{~h}$ after ibotenate injection. Bar represents mean length of the neocortical lesion in the sagittal fronto-occipital axis \pm SEM. Asterisks indicate difference from control $(* P<0.05, * * P<0.01$ in ANOVA with Dunnet's multiple comparison test). Control animals $(\mathrm{Ctrl})$ injected with ibotenate alone; the other experimental groups were either cotreated with ibotenate and $1 \mu \mathrm{g}$ VIP (VIP $0 \mathrm{~h}$ ) or were injected initially with ibotenate, and received a second injection of $1 \mu \mathrm{g}$ VIP at different times (VIP 2, 4, or 8 h) after the initial ibotenate injection. 


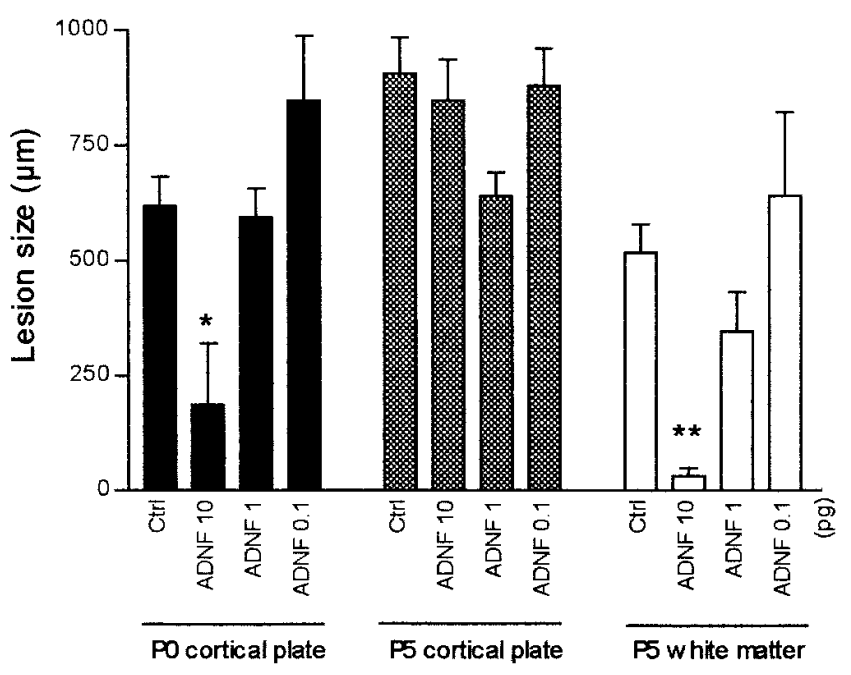

Figure 4. ADNF mimics VIP effects on excitotoxic neocortical lesions. Bar represents mean length of the neocortical lesion in the sagittal fronto-occipital axis \pm SEM. Asterisks indicate difference from control $(* P<0.05, * * P<0.01$ in ANOVA with Dunnet's multiple comparison test). Control animals ( $\mathrm{Ctrl}$ ) injected with ibotenate alone; $A D N F$, animals cotreated with ibotenate and ADNF.

fronto-occipital axis) (Fig. $2 A$ ). Cotreatment with lower doses of PACAP did not affect the size of the excitotoxic lesion (Fig. $2 A$ ). Coinjection of VIP and VA completely abolished the VIP protective effect against ibotenate-induced lesions (Fig. 2 A). ADNF-14 (10 pg) induced a significant protection against excitotoxic neuronal death $(67 \%$ reduction of mean length of the lesion in the sagittal fronto-occipital axis) (Fig. 4).

$V I P$-induced protection against ibotenate injections performed at P5. All P5 animals injected with ibotenate alone displayed cortical lesions (mean length of the lesion in the sagittal fronto-occipital axis: $906 \pm 78 \mu \mathrm{m}$ ) (Fig. $1 \mathrm{D}$ and Fig. $2 \mathrm{~B}$ ), and $88 \%$ of these animals also had large periventricular white matter cysts (mean length of the lesion in sagittal fronto-occipital axis: 516 $\pm 62 \mu \mathrm{m}$ ) (Fig. $1 D$ and Fig. $2 C$ ). The cortical lesion was typical, with a dramatic neuronal loss in neocortical layers II, III, IV , V, VIa, and VIb, with an almost complete disappearance of neuronal cell bodies along the axis of ibotenate injection.

Cotreatment of P5 animals with ibotenate and either VIP, VA, SNV, PACAP, forskolin, or ADNF-14 had no significant effect on the ibotenate-induced neuronal death (Fig. $2 B$ and Fig. 4). In contrast, VIP provided a dose-dependent protection against the excitotoxic white matter cyst $(20,67$, and $85 \%$ decrease of the mean lesion length in the sagittal fronto-occipital axis with $0.01,0.1$, and $1 \mu \mathrm{g}$ VIP, respectively) (Fig. $1 e$ and Fig. $2 C$ ). With the highest dose of VIP, $38 \%$ of cotreated animals displayed completely normal white matter. $1 \mu \mathrm{g}$ heat-inactivated VIP had no protective effect on white matter lesions. A significant VIP protection against excitotoxic white matter damages was observed when VIP was coinjected with ibotenate, or was injected up to $4 \mathrm{~h}$ after ibotenate administration (Fig. 3). As at P0, coinjection of SNV reproduced VIP protective effects against excitotoxic lesions (93\% lesion size reduction and absence of detectable histological lesion in $50 \%$ of treated animals) (Fig. $1 f$ and Fig. $2 C$ ). Co-treatment with VA and ibotenate aggravated the excitotoxic lesion (64\% increase of white matter cyst size in the sagittal fronto-occipital axis) (Fig. $2 C$ ). Coinjection of VIP and VA completely abolished VIP protection against ibotenate-induced lesions (Fig. $2 C$ ). Different doses of forskolin had no detectable effect on ibotenate-induced white matter lesions (Fig. 2 C). While lower doses of PACAP had no detectable protective effects, animals coinjected with ibotenate and $1 \mu \mathrm{g}$ PACAP had a tendency to display smaller white matter cysts (49\% lesion size reduction) that were not statistically significant. ADNF-14 (10 pg) significantly protected the neocortical white matter against ibotenate-induced lesions (94\% lesion size reduction in the sagittal fronto-occipital axis, and absence of detectable histological lesion in $60 \%$ of animals) (Fig. 4).

Distribution of VIP binding sites in the P0 and P5 neocortex (Fig. 5). In the P0 mouse brain, VIP binding was widespread, moderately dense, with higher densities seen in regions containing dividing neuroepithelial cells such as the developing striatum (Fig. $5 a$ ). Throughout most of the neopallium, binding was moderate, but exhibited slightly higher levels in the molecular layer, the highest levels in the periventricular neuroepithelium, and the lowest levels in the white matter (Fig. 5a). In the presence of $1 \mu \mathrm{M} \mathrm{SNV}, \sim 70 \%$ of the VIP binding was displaced throughout all neopallium layers, including the remaining neuroepithelium (Fig. $5 b$ ). The high binding in the neuroepithelium of the striatum was also displaced by SNV. The labeled VIP binding in the brain was specific since it was displaced by $1 \mu \mathrm{M}$ VIP (Fig. $5 c$ ).

In the P5 mouse brain, VIP binding was also widespread, moderately dense, and exhibited a higher density in the striatum compared with adjacent brain regions (Fig. $5 d$ ). VIP binding was fairly uniform throughout the neocortical plate, however, the deeper layers had the highest density of binding sites (Fig. $5 d$ ). SNV ( $1 \mu \mathrm{M} \mathrm{SNV}$ ) displaced $\sim 65 \%$ of the VIP binding in the superficial neocortical layers, and $\sim 75 \%$ of the binding in the deeper layers (Fig. $5 e$ ). As in P0 mouse brain, VIP binding was low in white matter of the P5 mouse brain.

\section{Discussion}

The most salient feature of this study is the demonstration that VIP potently protects the developing brain from ibotenate insults. VIP is particularly efficient in preventing excitotoxic neuronal loss in cortical layers V-VIa at $\mathrm{P} 0$, and white matter cystic lesions at P5. In contrast, VIP has no significant effect on ibotenate-induced neuronal loss in cortical layers II-VI at P5. These protective effects of VIP are in agreement with previous in vitro data showing that VIP prevents embryonic neural cell death (18-21). Recent experiments have also reported that c-fos upregulation induced by nontoxic low concentrations of glutamate can be potentiated by VIP, suggesting possible interrelations between VIP and glutamatergic agents (30). Furthermore, in nonneural tissues, NMDA-induced lung edema can be attenuated by VIP (31).

In vitro, the survival-promoting action of VIP on neurons is mediated by astrocytes that display VIP receptors, and release, after VIP stimulation, neurotrophic factors including ADNF, IL-1, and protease nexin 1 (18, 24-26). In the present model, although direct effects of VIP on cortical neurons and on white matter axons cannot be excluded, both cortical plate and white matter protective effects of VIP could be mediated by astrocytes and glial-released factors, as demonstrated by the protective effects of ADNF administration. 


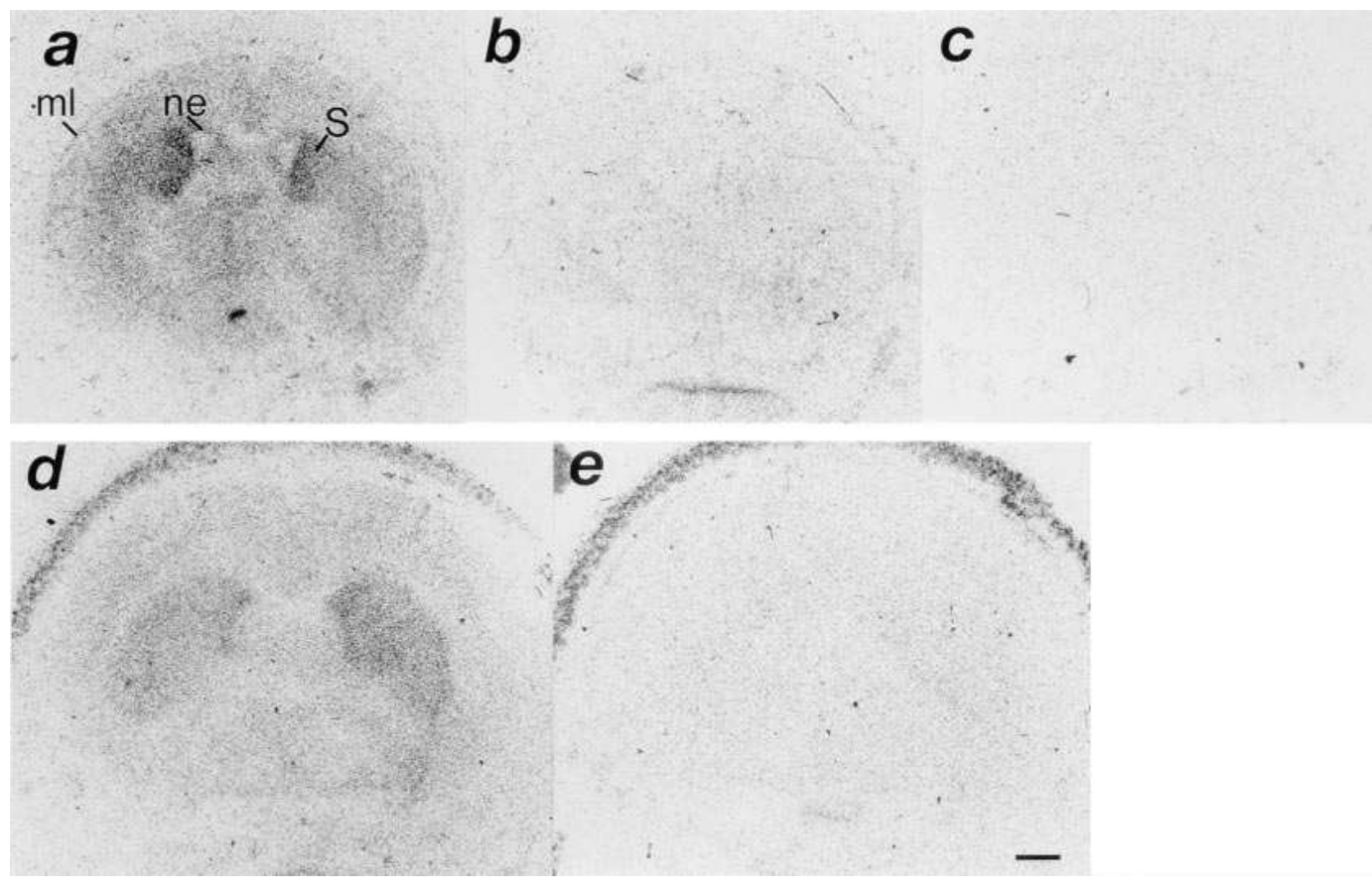

Figure 5. Autoradiographs of $\left[{ }^{125}\right.$ I]VIP binding in coronal sections of P0 and P5 brains. Tissue slices were treated under conditions described in Methods. (a) Total VIP binding in $\mathrm{P} 0$ mouse brain. (b) Section of P0 mouse brain adjacent to $a$, VIP binding in the presence of $1 \mu \mathrm{M} \mathrm{SNV}$. (c) Section of $\mathrm{P} 0$ mouse brain adjacent to $b$, VIP binding in the presence of $1 \mu \mathrm{M}$ VIP. (d) Total VIP binding in P5 mouse brain. (e) Section of P5 mouse brain adjacent to $d$, VIP binding in the presence of $1 \mu \mathrm{M} \mathrm{SNV}$. Bar, $500 \mu \mathrm{m}$. $\mathrm{ml}$, molecular layer; $n e$, neuroepithelium; $S$, striatum.

VIP rescued P0 (but not P5) neocortical neurons from excitotoxic cell death, although VIP binding sites (which do not discriminate between VIP receptor subtypes and between neuronal and glial populations) were present in the P0 and P5 neocortical plates. Similarly, VIP protected P5 white matter, but not P5 neurons from excitotoxicity, although this differential VIP action was not explained by the injection procedure (see Methods). Several hypotheses could explain these differences: (a) the mechanism of ibotenate toxicity is different at $\mathrm{P} 0$ and P5 and/or between cortical plate and white matter; (b) P0 and P5 neurons exhibit different sensitivity to glia-derived neurotrophic factors; (c) diffusability or degradation of VIP could be different in neocortical layers at $\mathrm{P} 0$ compared with $\mathrm{P} 5$, or in white matter compared with neocortical layers at P5; $(d)$ at P0, VIP receptors are abundant on astrocytes, inducing the release of neurotrophic factors while, at $\mathrm{P} 5$, most VIP receptors are present on neurons; and $(e)$ the subtype of VIP receptors present in the neocortex changes between P0 and P5, or between P5 cortical plate and P5 white matter.

While VIP injections given up to $4 \mathrm{~h}$ after ibotenate administration at P5 provide a significant protection against white matter lesions, VIP seems to be mostly preventive and poorly therapeutic against excitotoxic lesions at P0, as VIP has to be coinjected with ibotenate to observe a protective effect at $\mathrm{P} 0$. The molecular basis of this disparity in VIP effects at P0 and P5 is still unclear, and could reflect differences between white matter cells and cortical neurons. Alternatively, diffusability and degradation of VIP could be different after ibotenate injection in $\mathrm{P} 0$ cortical plate and in $\mathrm{P} 5$ white matter. In particular, we observed a higher frequency of hemorrhage at the second delayed injection in P0 brains when compared to P5 pups (Gressens, P., and S. Marret, personal communication).

The protection afforded by VIP treatment in the ibotenateinduced lesions seems to be specific for VIP and/or a VIPrelated molecule (see below), and is likely receptor-mediated. Several lines of evidence support this statement: (a) VIP ef- fects are dose dependent; (b) VIP-induced protection is suppressed by cotreatment with VA, a specific VIP antagonist; (c) injection of VA aggravates ibotenate-induced lesions; and $(d)$ VIP binding sites are present in the neocortical layers where VIP exhibits protective effects.

Receptors and transduction pathways underlying VIP effects. As previously mentioned, PACAP and VIP share some common receptors (for review see reference 27). Two of them have been cloned recently, and tentatively called VIP-1/ PACAP-2 (40, 41) and VIP-2/PACAP-3 receptors (42, 43). PACAP, but not VIP, also acts on some PACAP-1 receptors (44). Similarly, specific VIP receptors (which we propose to call VIP-3 receptors) not shared by PACAP have not yet been cloned, although their existence, based on physiological effects of VIP not reproduced by PACAP, has been hypothesized $(23,45)$.

Two transduction pathways have been reported for VIP and PACAP: (a) VIP and PACAP can stimulate the production of cAMP $(28,29)$; and $(b)$ recent studies have shown that subnanomolar concentrations of VIP and PACAP stimulate the accumulation of intracellular calcium and increase inositol phosphates in astrocyte cultures $(46,47)$, and that VIP produces translocation of protein kinase $\mathrm{C}-\alpha,-\delta$ and $-\xi$ isozymes (48).

In our mouse model of excitotoxicity, the neuronal protection induced by VIP at P0 is unlikely to be mediated through a VIP-PACAP or a PACAP receptor, since treatment with $1 \mu \mathrm{g}$ PACAP increases the size of the ibotenate-induced lesion. These data support the hypothesis of the existence, at least during brain development, of some specific VIP receptors not shared by PACAP. Since SNV, but not forskolin, protects the cortical plate against the excitotoxic cascade, VIP protective effects at $\mathrm{P} 0$ seem to be cAMP independent, and mediated by an alternate transduction mechanism, possibly involving intracellular calcium, phosphate inositol, and some protein kinase C. This observation is confirmed by the displacement of the labeled VIP from cortical binding sites by SNV, suggesting that $70 \%$ of the VIP binding sites in the neocortex at this age are 
not linked to cAMP. These data are in agreement with previous cell culture studies, showing that subnanomolar concentration of VIP and SNV, which do not activate adenylate cyclase, promote neuronal survival $(19,20,36,37)$. In contrast, negative effects of high-dose PACAP on excitotoxic lesions at P0 could be mediated by cAMP, as forskolin also aggravates ibotenate-induced lesions.

At P5, after ibotenate injection, VIP and SNV provide a significant protection ( $85-88 \%$ reduction of lesion size) in the white matter in contrast to PACAP and forskolin, which do not induce a statistically significant reduction of lesion size. These data suggest that, as at P0, the hypothesized VIP-3 receptor is involved, and uses a cAMP-independent transduction pathway to prevent ibotenate-induced white matter lesions. Although data are not statistically significant, $1 \mu \mathrm{g}$ PACAP may provide a $50 \%$ protection against ibotenate white matter lesions. Based on the available data on receptors, the tendency of PACAP to protect partially against excitotoxic white matter lesions could be explained by activation of the specific PACAP-1 receptor or a common VIP-PACAP receptor.

Implications for human fetuses and preterm neonates. The administration of ibotenate in the developing mouse brain recapitulates the sequence of hypoxic-like CNS lesions observed in human fetuses and preterm/term neonates (10). In the present study, we have shown that VIP and SNV provide significant protection against lesions mimicking microgyria (neuronal loss predominating in layers $\mathrm{V}-\mathrm{VIa}$ at $\mathrm{P} 0$ ) and periventricular leukomalacias (white matter cysts at P5) that seem to occur in human brains more frequently between 14 and 28 postconceptional wk $(11,12)$ and 24 and 32 postconceptional wk $(8,15,16)$, respectively. The present data support the hypothesis of a disturbed balance between protective mechanisms (such as free radical scavengers and growth factors including VIP) and toxic factors (such as excitatory amino acids, free radicals, nitric oxide, cytokines, and hypoxic-ischemic conditions) as the pathophysiological mechanism leading to some hypoxic-like lesions of the developing brain.

The maternal circulation provides not only nutrients for the developing fetus, but also hormones and growth factors such as insulin (49), thyroid hormones (50), steroids (51), G-CSF (52), TGF 3 (53), and VIP (54). Transplacental transfer of several of these factors is probably limited to the early stages of brain development, and the fetus produces some of these factors at later stages of development. Premature delivery, however, potentially induces a brutal loss of the maternal supply of molecules that are not produced or not in sufficient amount by the fetus. With regard to VIP, this peptide is present in human maternal and fetal circulations throughout the whole gestation (55), but no data are available on the production of VIP by the human fetal brain. VIP mRNA begins to be detected easily by in situ hybridization after $120 \mathrm{~d}$ of gestation in monkey brain (56), and during the first postnatal week in rat brain (57), although Waschek and collaborators have described recently mouse hindbrain cells expressing VIP mRNA as early as E11 (58). Future studies will have to determine the importance of these early cells producing VIP in comparison to circulating VIP in brain development and neuroprotection. In particular, further analyses are required to correlate the risk of cerebral palsy with circulating VIP levels in premature infants.

Beyond clues for a better understanding of the pathophysiology of brain lesions observed in human fetuses and preterm neonates, the present data also provide experimental data to support intervention studies to prevent such brain lesions. Glutamate receptor antagonists and inhibitors of glutamate release (for review see reference 9), free radical scavengers (59), growth factors including nerve growth factor (60), and insulinlike growth factor 1 (61), have been shown to protect partially rodent brains against excitotoxic and/or hypoxic-ischemic damages. VIP derivatives could represent an alternate approach to treat these disorders in premature infants. Highly lipophilic SNV is able to reach the CNS after peripheral administration (37), and has potentially fewer side effects than VIP since it does not stimulate cAMP production (36-38). ADNF and derivatives could also represent an interesting approach to prevent excitotoxic lesions in premature infants.

Conclusion. This study demonstrates that, in a developing mouse model of excitotoxic neural cell death, VIP prevents lesions that strikingly mimick polymicrogyria and periventricular leukomalacia. This VIP protection seems to be mediated largely by a specific novel VIP receptor using a cAMP-independent transduction pathway, probably leading to the release of ADNF. SNV, a VIP-lipophilic analog, and ADNF could represent new pharmacological tools to be tested in human premature infants at high risk of cerebral palsy.

\section{Acknowledgments}

The authors thank Dr. Annie Delpech, Dr. Bertrand Delpech, and Dr. Catherine Nessmann for their support, and Ms. Leslie Besse, Ms. Eliane Abdelouab, Ms. Maxette Pierin, Mr. Pascal Blain, and Mrs. Sara Rubinraut for skillful technical assistance.

This work was supported by grants from the Fondation de France (Paris, France), from the Fondation pour la Recherche Médicale (Paris, France), and from the Centre Hospitalier Universitaire de Rouen (Rouen, France).

\section{References}

1. Hagberg, B., G. Hagberg, I. Olow, and L. v. Wendt. 1996. The changing panorama of cerebral palsy in Sweden. VII. Prevalence and origin in the birth year period 1987-90. Acta Paediatr. 85:954-960.

2. Pharoah, P., T. Cooke, R.W. Cooke, and L. Rosenbloom. 1990. Birthweight specific trends in cerebral palsy. Arch. Dis. Child. 65:602-606.

3. Nelson, K.B., and J.H. Ellenberg. 1986. Antecedents of cerebral palsy. Multivariate analysis of risk. N. Engl. J. Med. 315:81-86.

4. Evrard, P., N. Miladi, C. Bonnier, and P. Gressens. 1992. Normal and abnormal development of the brain. In Child Neuropsychology, I. Rapin and S.J. Segalowitz, editors. Handbook of Neuropsychology. Elsevier Science B.V., Amsterdam. 11-44.

5. Evrard, P., S. Marret, and P. Gressens. 1995. Environmental determinants of brain development, with a special emphasis on the excitotoxic cascade at the consecutive developmental steps. In Aktuelle Neuropädiatrie. D. Rating, editor. Ciba-Geigy Verlag, Wehr, Germany. 22-33.

6. Volpe, J.J. 1995. Neurology of the Newborn. W.B. Saunders Co., Philadelphia. 876 pp.

7. Murphy, D.J., S. Sellers, I.Z. MacKenzie, P.L. Yudkin, and A.M. Johnson. 1995. Case-control study of antenatal and intrapartum risk factors for cerebral palsy in very preterm singleton babies. Lancet. 346:1449-1454.

8. Zupan, V., P. Gonzalez, T. Lacaze-Masmonteil, C. Boithias, A.M. d'Allest, M. Dehan, and J.C. Gabilan. 1996. Periventricular leukomalacia: risk factors revisited. Dev. Med. Child Neurol. 38:1061-1067.

9. McDonald, J.W., and M.V. Johnston. 1990. Physiological and pathophysiological roles of excitatory amino acids during central nervous system development. Brain Res. Rev. 15:41-70.

10. Marret, S., R. Mukendi, J.F. Gadisseux, P. Gressens, and P. Evrard. 1995. Effect of ibotenate on brain development: an excitotoxic mouse model of microgyria and posthypoxic-like lesions. J. Neuropathol. Exp. Neurol. 54:358-370.

11. Evrard, P., M.C. Belpaire, G. Boog, N. Elkhazen, J.F. Gadisseux, B. Le Marec, J.P. Misson, J.J. Santini, and M. Van Lierde. 1985. Diagnostic anténatal des affections du SNC: résultats préliminaires d'une étude multicentrique européenne. J. Français d'Echographie. 2:123-126.

12. Barkovich, A.J., P. Gressens, and P. Evrard. 1992. Formation, matura- 
tion, and disorders of brain neocortex. Am. J. Neuroradiol. 13:423-446.

13. Barmada, M.A., J. Moossy, and R.M. Shuman. 1979. Cerebral infarcts with arterial occlusion in neonates. Ann. Neurol. 6:495-502.

14. Volpe, J.J. 1992. Perinatal hypoxic-ischemic brain injury: an overview. In Fetal and Perinatal Neurology. Y. Fukuyama, Y. Suzuki, S. Kamoshita, and P. Casaer, editors. Karger, Basel, Switzerland. 232-252.

15. de Vries, L.S., J.S. Wigglesworth, R. Regev, and L.M.S. Dubowitz. 1988. Evolution of periventricular leukomalacia during the neonatal period and infancy. Early Hum. Dev. 17:205-219.

16. Hope, P.L., S.J. Gould, S. Howard, P.A. Hamilton, A.M. De L. Costello, and E.O.R. Reynolds. 1988. Precision of ultrasound diagnosis of pathologically verified lesions in brains of very preterm infants. Dev. Med. Child Neurol. 30: 457-471.

17. Marret, S., P. Gressens, J.F. Gadisseux, and P. Evrard. 1995. Prevention by magnesium of excitotoxic neuronal death in the developing brain: an animal model for clinical intervention. Dev. Med. Child Neurol. 37:473-484.

18. Brenneman, D.E., T. Nicol, D. Warren, and L.M. Bowers. 1990. Vasoactive intestinal peptide: a neurotrophic releasing agent and an astroglial mitogen. J. Neurosci. Res. 25:386-394.

19. Brenneman, D.E., L.E. Eiden, and R.E. Siegel. 1985. Neurotrophic action of VIP on spinal cord cultures. Peptides. 6 (Suppl.):35-39.

20. Brenneman, D.E., and L.E. Eiden. 1986. Vasoactive intestinal peptide and electrical activity influence neuronal survival. Proc. Natl. Acad. Sci. USA. 83:1159-1162.

21. Pincus, D.W., E.M. DiCicco-Bloom, and I.B. Black. 1990. Vasoactive intestinal peptide regulates mitosis, differentiation and survival of cultured sympathetic neuroblasts. Nature (Lond.). 343:564-567.

22. Gressens, P., J.M. Hill, I. Gozes, M. Fridkin, and D.E. Brenneman. 1993. Growth factor function of vasoactive intestinal peptide in whole cultured mouse embryos. Nature (Lond.). 362:155-158.

23. Gressens, P., J.M. Hill, B. Paindaveine, I. Gozes, M. Fridkin, and D.E. Brenneman. 1994. Severe microcephaly induced by blockade of vasoactive intestinal peptide function in the primitive neuroepithelium of the mouse. J. Clin. Invest. 94:2020-2027.

24. Brenneman, D.E., and I. Gozes. 1996. A fentomolar-acting neuroprotective peptide. J. Clin. Invest. 97:2296-2307.

25. Brenneman, D.E., J.M. Hill, G.W. Glazner, I. Gozes, and T.M. Phillips. 1995. Interleukin-1 alpha and vasoactive intestinal peptide: enigmatic regulation of neuronal survival. Int. J. Dev. Neurosci. 13:187-200.

26. Festoff, B.E., P.G. Nelson, and D.E. Brenneman. 1996. Prevention of activity-dependent neuronal death: vasoactive intestinal polypeptide stimulates astrocytes to secrete the thrombin-inhibiting, neurotrophic serpin, protease nexin. J. Neurobiol. 30:255-266.

27. Arimura, A. 1992. Receptors for pituitary adenylate cyclase-activating polypeptide. Comparison with vasoactive intestinal peptide receptors. Trends Endocrinol. Metab. 3:288-294.

28. Magistretti, P.J., and M. Schorderet. 1984. VIP and noradrenaline act synergistically to increase cyclic AMP in cerebral cortex. Nature (Lond.). 308: 280-282.

29. Gozes, I., S.K. McCune, L. Jacobson, D. Warren, T.W. Moody, M. Fridkin, and D.E. Brenneman. 1991. An antagonist to vasoactive intestinal peptide: effects on cellular functions in the central nervous system. J. Pharmacol. Exp. Ther. 257:959-966.

30. Martin, J.L., D. Gasser, and P.J. Magistretti. 1995. Vasoactive intestinal peptide and pituitary adenylate cyclase-activating polypeptide potentiate $c$-fos expression induced by glutamate in cultured cortical neurons. J. Neurochem. 65: $1-9$.

31. Said, S.I., H.I. Berisha, and H. Pakbaz. 1996. Excitotoxicity in the lung: $\mathrm{N}$-methyl-D-aspartate-induced nitric oxide-dependent, pulmonary edema is attenuated by vasoactive intestinal peptide and by inhibitors of poly(ADP-ribose) polymerase. Proc. Natl. Acad. Sci. USA. 93:4688-4692.

32. Gozes, I., E. Meltzer, S. Rubinraut, and D.E. Brenneman. 1989. Vasoactive intestinal peptide potentiates sexual behavior: inhibition by a novel antagonist. Endocrinology. 125:2945-2949.

33. Gozes, Y., D.E. Brenneman, M. Fridkin, R. Asofsky, and I. Gozes. 1991. A VIP antagonist distinguishes VIP receptors in spinal cord and lymphocytes. Brain Res. 540:319-321.

34. Hill, J.M., R.F. Mervis, J. Politi, S.K. McCune, I. Gozes, M. Fridkin, and D.E. Brenneman. 1994. Blockade of VIP during neonatal development induces neuronal damages and increases VIP and VIP receptors in brain. Ann. NY. Acad. Sci. 739:211-225.

35. Hill, J.M., I. Gozes, J.L. Hill, M. Fridkin, and D.E. Brenneman. 1991. Vasoactive intestinal peptide antagonist retards the development of neonatal behaviors in the rat. Peptides USA. 12:187-192.

36. Gozes, I., G. Lilling, R. Glazer, A. Ticher, I.E. Ashkenazi, A. Davidson, S. Rubinraut, M. Fridkin, and D.E. Brenneman. 1995. Superactive lipophilic peptides discriminate multiple vasoactive intestinal peptide receptors. J. Pharmacol. Exp. Ther. 273:161-167.

37. Gozes, I., A. Bardea, A. Reshef, R. Zamostiano, S. Zhukovsky, S. Ru- binraut, M. Fridkin, and D.E. Brenneman. 1996. Neuroprotective strategy for Alzheimer disease: intranasal administration of a fatty neuropeptide. Proc. Natl. Acad. Sci. USA 93:427-432.

38. Gozes, I., A. Reshef, D. Salah, S. Rubinraut, and M. Fridkin. 1994. Stearyl-norleucine-VIP, a novel VIP analogue for noninvasive impotence treatment. Endocrinology. 134:2121-2125.

39. Hill, J.M., A. Harris, and D.I. Hilton-Clarke. 1992. Regional distribution of guanine nucleotide-sensitive and guanine nucleotide-insensitive vasoactive intestinal peptide receptors in rat brain. Neuroscience. 48:925-932.

40. Ishiara, T., R. Shigemoto, K. Mori, K. Takahashi, and S. Nagata. 1992. Functional expression and tissue distribution of a novel receptor for vasoactive intestinal peptide. Neuron. 8:811-819.

41. Sreedharan, S.P., D.R. Patel, J.X. Huang, and E.J. Goetzl. 1993. Cloning and functional expression of a human neuroendocrine vasoactive intestinal peptide receptor. Biochem. Biophys. Res. Commun. 193:546-553.

42. Lutz, E.M., W.J. Sheward, K.M. West, J.A. Morrow, G. Fink, and A.J. Harmar. 1993. The VIP2 receptor: molecular characterisation of a cDNA encoding a novel receptor for vasoactive intestinal peptide. FEBS (Fed. Eur. Biochem. Soc.) Lett. 334:3-8.

43. Adamaou, J.E., N. Aiyar, S. Van Horn, and N.A. Elshourbagy. 1995. Cloning and functional characterization of the human vasoactive intestinal peptide (VIP)-2 receptor. Biochem. Biophys. Res. Commun. 209:385-392.

44. Spengler, D., C. Waeber, C. Pantaloni, F. Hoelboer, J. Bockaert, P.H. Seeburg, and L. Journot. 1993. Differential signal transduction by five splice variants of the PACAP receptor. Nature (Lond.). 365:170-175.

45. Gressens, P., B. Paindaveine, J.M. Hill, D.E. Brenneman, and P. Evrard. 1997. Growth factor properties of VIP during early brain development: whole embryo culture and in vivo studies. Ann. NY Acad. Sci. 814:152-160.

46. Fatatis, A., L.A. Holtzclaw, R. Avidor, D.E. Brenneman, and J.T. Russel. 1994. Vasoactive intestinal peptide increases intracellular calcium in astroglia: synergism with alpha-adrenergic receptors. Proc. Natl. Acad. Sci. USA 91: 2036-2040.

47. Arimura, A., A. Somogyvari-Vigh, C. Well, R.C. Fiore, I. Tatsuno, V. Bay, and D.E. Brenneman. 1994. PACAP functions as a neurotrophic factor. Ann. NY Acad. Sci. 739:228-243.

48. Olah, Z., C. Lehel, W.B. Anderson, D.E. Brenneman, and D.V. Agoston. 1994. Subnanomolar concentration of VIP induces the nuclear translocation of proteine kinase $\mathrm{C}$ in neonatal rat cortical astrocytes. J. Neurosci. Res. 39: $355-363$.

49. Unterman, T.G., T.A. Buchanan, and N. Freinkel. 1989. Access to maternal insulin to the rat conceptus prior to allantoic placentation. Diabetes Res. Clin. Pract. 10:115-120.

50. Obregon, M.J., J. Mallol, R. Pastor, and G. Morreale de Escobar. 1984 L-thyroxine and 3,3',5'-triiodo-L-thyroxine in rat embryos before onset of fetal thyroid function. Endocrinology. 114:305-307.

51. Page, E.W., C.A. Villee, and D.B. Villee. 1981. Human reproduction. In Essentials of Reproductive and Perinatal Medicine. 3rd edition. W.B. Saunders Co., Philadelphia. $526 \mathrm{pp}$.

52. Medlock, E.S., D.L. Kaplan, M. Cecchini, T.R. Ulich, J. del Castillo, and J. Andresen. 1993. Granulocyte-macrophage colony stimulating factor crosses the placenta and stimulates fetal rat granulopoiesis. Blood. 81:916-922.

53. Letterio, J.J., A.G. Geiser, A.B. Kulkarni, N.S. Roche, M.B. Sporn, and A.B. Roberts. 1994. Maternal rescue of transforming growth factor-beta1 null mice. Science (Wash. DC). 264:1936-1938.

54. Hill, J.M., S.K. McCune, R.J. Alvero, G.W. Glazner, K.A. Henins, S.F. Stanziale, J.R. Keimowitz, and D.E. Brenneman. 1996. Maternal vasoactive intestinal peptide and the regulation of embryonic growth in rodents. J. Clin. Invest. 97:202-208.

55. Ottesen, B., H. Ulrichsen, J. Fahrenkrug, J.J. Larsen, G. Wagner, L. Schierup, and F. Sondergaard. 1982. Vasoactive intestinal polypeptide and the female genital tract: relationship to reproductive phase and delivery. Am. $J$. Obstet. Gynecol. 143:414-420.

56. Hayashi, M. 1991. Ontogeny of some neuropeptides in the primate brain. Prog. Neurobiol. (Oxford). 38:231-260.

57. Hill, J.M., D.V. Agoston, P. Gressens, and S.K. McCune. 1994. Distribution of VIP mRNA and two distinct VIP binding sites in the developing rat brain: relation to ontogenic events. J. Comp. Neurol. 342:186-205.

58. Waschek, J.A., J. Ellison, D.T. Bravo, and V. Handley. 1996. Embryonic expression of vasoactive intestinal peptide (VIP) and VIP receptor genes. $J$. Neurochem. 66:1762-1765.

59. Thordstein, M., R. Bagenholm, K. Thiringer, and I. Kjellmer. 1993. Scavengers of free oxygen radicals in combination with magnesium ameliorate perinatal hypoxic-ischemic brain damage in the rat. Pediatr. Res. 34:23-26.

60. Holtzman, D.M., R.A. Sheldon, W. Jaffe, Y. Cheng, and D.M. Ferriero. 1996. Nerve growth factor protects the neonatal brain against hypoxic-ischemic injury. Ann. Neurol. 39:114-122.

61. Johnston, B.M., E.C. Mallard, C.E. Williams, and P.D. Gluckman. 1996. Insulin-like growth factor- 1 is a potent neuronal rescue agent after hypoxicischemic injury in fetal lambs. J. Clin. Invest. 97:300-308. 